\title{
Elevated WT1
}

National Cancer Institute

\section{Source}

National Cancer Institute. Elevated WT 1. NCI Thesaurus. Code C153235.

A finding indicating elevated concentrations of WT1 in a sample. 